\title{
Neoplasia of aortic intima
}

\author{
R. A. SLADDEN
}

From the Department of Pathology, Northampton General Hospital

SYNOPSIS Two cases of arterial obstruction, in the region of the aortic bifurcation, are described In both cases, cellular proliferation of neoplastic type was found to be causing the obstruction, an\& in one case small embolic metastases were found in the lower limbs and lungs. No primary tumouc was found in any site other than the aortic intima itself. Two apparently similar cases have beerp reported in recent years. It is suggested that this condition, although probably very rare, may be overlooked for several reasons unless obstructive aortic lesions are examined histologically as $\mathrm{a}$ routine.

CASE 1

E.D., a man aged 64 (No. N.G.H. B.144694), a stoker, had been a coal-miner in South Wales. In 1916, during Army service, a left orchidectomy was performed for varicocele. In 1955 he began having lumbago or sciatic pain. In November 1959 he had a 'black-out'. One month later he complained of fleeting joint pains, vague abdominal pain, slight swelling of the right foot, and pain and numbness in the toes. Six months later he developed intermittent claudication of the right leg, unrelieved by drugs and occurring sometimes at night. There was also some pain in the left leg and lumbosacral tenderness.

An area of staining of the skin over the right greater trochanter was seen, and a biopsy showed (Figs. 1 and 2) that beneath an area of ischaemia of the dermis there was a small arteriole filled with cellular tissue. The tissue appeared to be embolic in origin and malignant in nature.

Clinical, radiological, and biochemical tests (including serum prostatic acid phosphatase) were all negative. In the meantime, lower limb pain necessitated an aortogram. This showed a filling defect in the lower two inches of the aorta.

On 17 October 1960 aortic endarteriectomy was performed (Mr. E. E. T. Taylor). In its external appearance the aorta appeared normal apart from slight atheromatous degeneration. Some rather soft, fleshy material was removed from the aortic lumen and section showed the presence of histologically malignant tissue (Fig. 3), much of which was necrotic, although the surviving cellular areas were identical with the intravascular tissue seen in the skin biopsy.

After the operation the femoral pulses were normal, but pain persisted in the right buttock and leg. One month later a small nodule appeared in the skin on the lateral side of the right thigh.

The patient received at this time a short course of Trilekamine.

His condition slowly deteriorated, and he died on
30 March 1961 without showing any new clinica symptoms or signs other than those of a terminal broncho pneumonia.

\section{NECROPSY REPORT OF CASE 1}

Dr. W. E. Bryan performed the necropsy (P.M $198 / 61)$.

The body was severely wasted. A skin nodule was present in the upper part of the right thigh.

The thoracic viscera, aorta, iliac and femoraf arteries, kidneys, ureters, bladder and prostate were removed and fixed, the lungs having first been perfused.

The head and neck were normal. The salivary glands, pituitary gland, meninges, and brain were normal. The oesophagus, stomach, and intestines were normal.

The liver was normal in size, slightly mottled op cut section.

The gall bladder, bile ducts, pancreas, anc suprarenal glands were normal. (The fixed viscerp were examined four weeks later.)

The heart weighed $300 \mathrm{~g}$. The heart valves werg normal, the myocardium and endocardium not remarkable. The coronary arteries were athero matous but not significantly occluded. The aorta was moderately atheromatous.

A few centimetres above the aortic bifurcation was a firm, greyish, nodular, irregular mass of tissuథ (Fig. 4). The main mass was situated from 3.0 t $\sigma^{+}$ $5.5 \mathrm{~cm}$. above the aortic bifurcation, measuring $2.5 \times 2.5 \times 0.5 \mathrm{~cm}$. Similar nodules were als present at the aortic bifurcation, partly blocking the common iliac arteries. At the entrance to the righ 9 common iliac artery the nodular mass measure 
$1.5 \times 1.2 \times 0.7 \mathrm{~cm}$. These arteries were patent below the obstruction, but, on the right side, the lumina of the external iliac and deep circumflex arteries were occluded.

The lungs showed extensive bronchopneumonic consolidation. The bronchi were dissected but no primary bronchial tumour was found. There were no large tumour masses in the lung parenchyma, but three small areas of pleural thickening and subpleural infiltration were found. Two of these areas were in the right middle lobe, the other was in the left lower lobe. The largest of the areas measured $0.8 \times 0.8 \times 0.2 \mathrm{~cm}$.

The spleen was not enlarged but appeared slightly infiltrated.

The kidneys were normal for a man of this age, apart from a haemorrhagic cyst at the corticomedullary junction in the right kidney $0.5 \mathrm{~cm}$. in diameter.

The ureters, bladder and prostate, and the thyroid gland were normal.

\section{HISTOLOGY OF CASE 1}

SKIN BIOPSY (S.H. 2556/60) A dermal arteriole in the thigh is completely blocked by cellular tissue, cytologically malignant in type (Figs. 1 and 2). The malignant cells show large pale vesicular nuclei of irregular outline with prominent nucleoli. A few mitotic cells are present. The cytoplasm is indistinct, rather foamy, with a slightly eosinophil staining reaction. The cellular mass shows, in places, an endothelial lining distinct from the endothelium of the arteriole.

SKIN OF THIGH (P.M. 198/61) A dermal arteriole is completely blocked by organized fibrous tissue. There is fairly widespread infiltration of the dermis by malignant cells, also dermal fibrosis.

AORTA The endarteriectomy specimen (S.H. 3375/ 60) consists of numerous fragments of friable soft pinkish-white tissue. The material is largely composed of necrotic cellular tissue in which cell ghosts are visible. Thrombotic material is also present. Around the periphery of the necrotic areas are zones of well-preserved cellular tissue (Fig. 3) similar to that found in the skin biopsy.

Periodic-acid-Schiff stain gave negative staining in both the cellular and necrotic zones. Mucicarmine and Alcian blue gave negative staining. With polychrome methylene blue the cell cytoplasm appears faintly metachromatic. Reticulin impregnation (Lendrum, 1947) gave a clear picture. Most of the cells are separated by well-impregnated fibrils, though small groups of cells are sometimes sur-

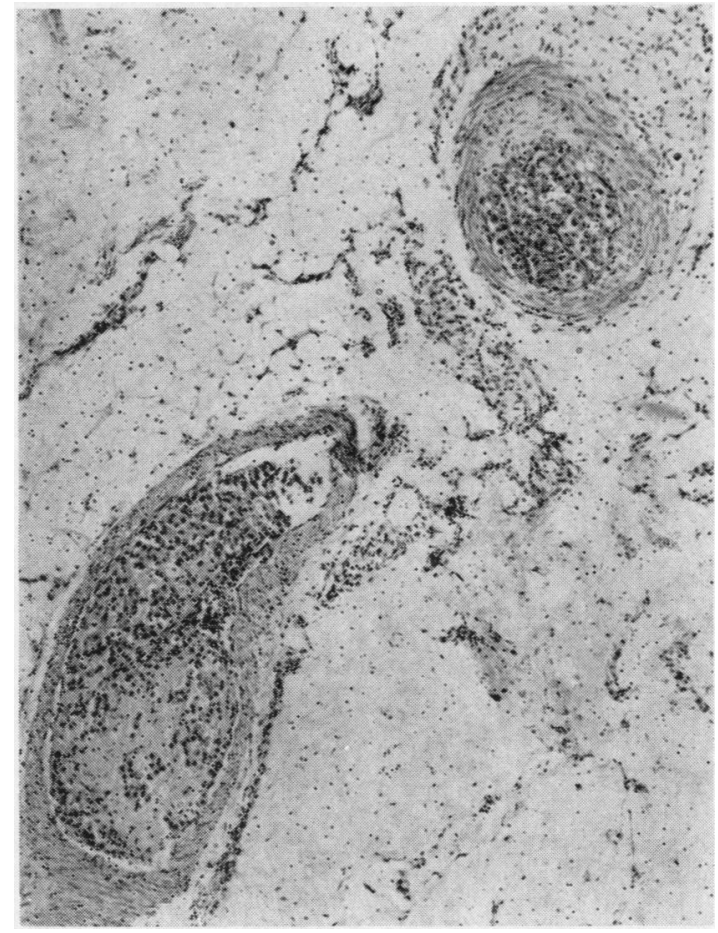

FIG. 1. Case 1. Skin biopsy (S.H. 2556/60). Tumour emboli in dermal arterioles. Haematoxylin and eosin $\times 46$.

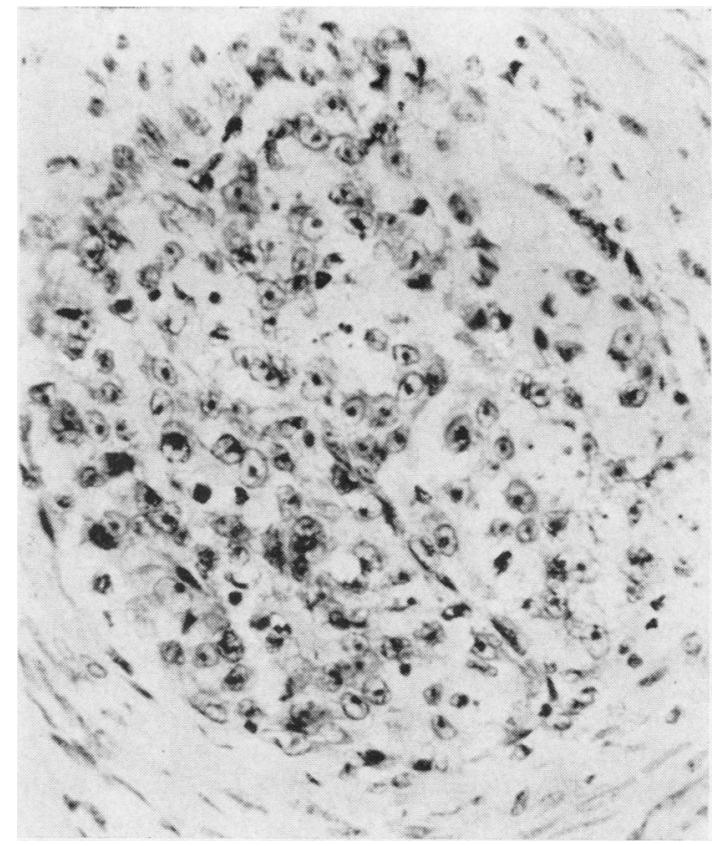

FIG. 2. Case 1. Skin biopsy (S.H. 2556/60). Tumour cells in the smaller of the two blood vessels shown in Figure 1. Haematoxylin and eosin $\times 200$. 


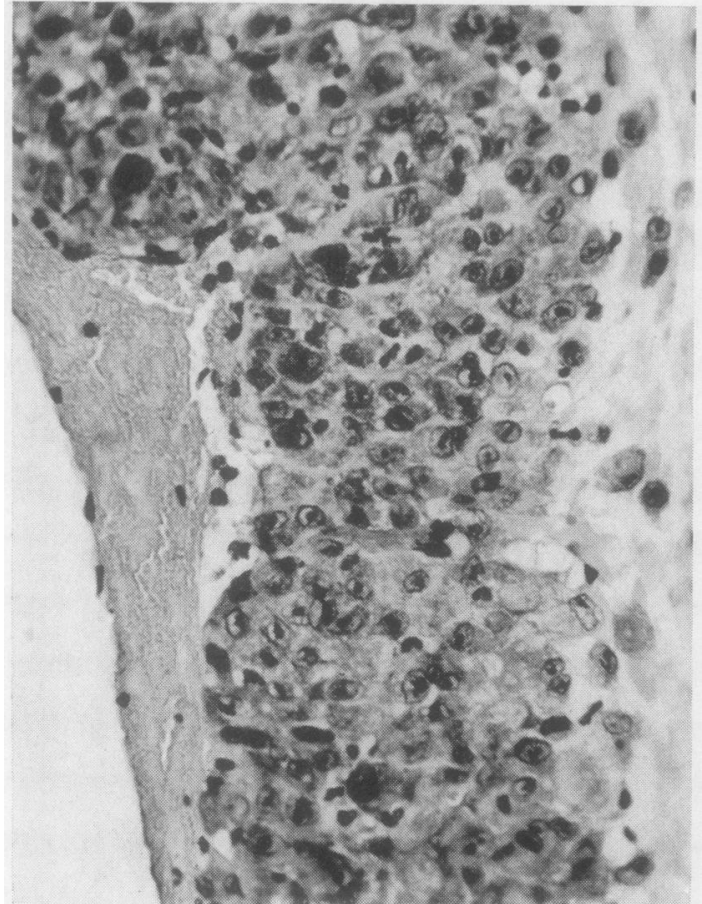

FIG. 3 .

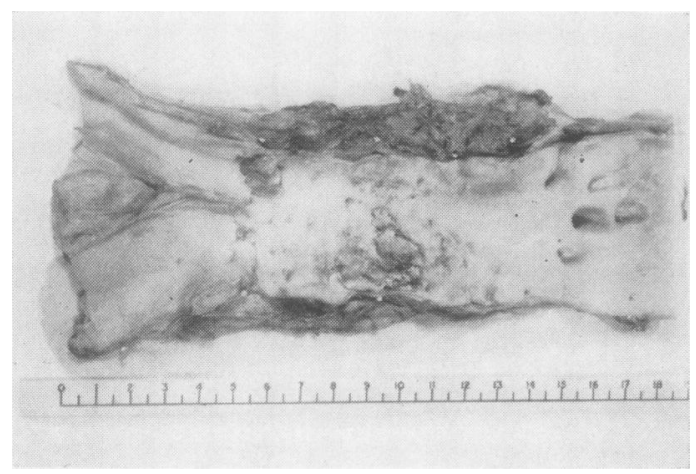

FIG. 4.

rounded by fibrils (Fig. 5). In the necrotic zones the fibrils are present peripherally but are absent centrally. The pattern is more suggestive of a sarcoma than of a carcinoma.

The aortic wall itself shows a fairly marked degree of atheromatous degeneration, scarcely excessive for a man of this age.

In the area overlying the endarteriectomy suture, the nodules of tissue are absent but the 'intima' is replaced by tumour cells.

Slight granulomatous reaction to the suture material is seen in the aortic wall. It is possible that

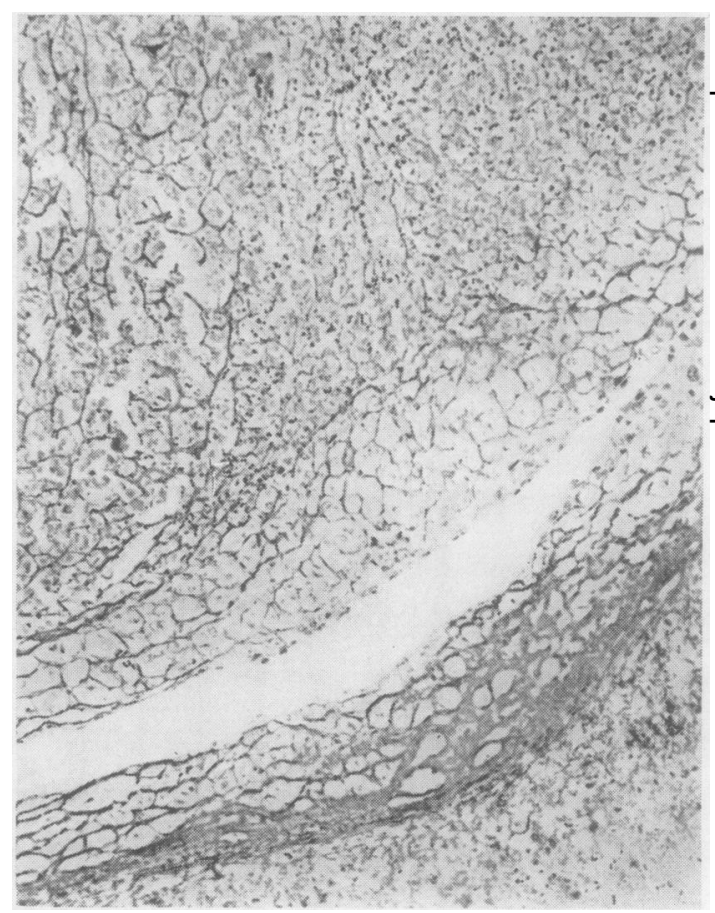

FIG. 5.

FIG. 3. Case 1. Aortic endarteriectomy specimen (S.H. 3375/60). Cellular and necrotic zones of tumour tissue, separated by a thin layer of thrombus from the aortic $\overline{0}$ lumen. Haematoxylin and eosin $\times 160$.

FIG. 4. Case 1. Opened aorta. Two main areas of nodular tumour formation are seen. The endarteriectomy suture $\frac{0}{8}$ line is opposite the $6 \mathrm{~cm}$. mark. Atheroma is not unduly severe.

FIG. 5. Case 1. Material from aorta. Pattern of argyrophil fibrils in cellular and necrotic areas. The cleft is lined by윽 cellular tissue. Reticulin impregnation $\times 120$.

the vasa vasorum of the aorta are in tumour cells, but otherwise the media and adventis show no neoplastic involvement.

RIGHT EXTERNAL ILIAC ARTERY This vessel is completely blocked by tissue similar to that in the aorta.

LUNGS The nodule on the surface of the left lung $\frac{\vec{C}}{\overparen{C}}$ is composed of individual tumour cells or clumps of tumour cells, set in a fibrous stroma with some@ fibrous reaction of the neighbouring pleura and ano 
overlying fibrinous exudate. Deep to this lesion is a small blood vessel blocked by tumour tissue.

One of the pleural nodules from the right middle lobe shows only some pleural fibrosis. The other reveals tumour infiltration with a marked pleomorphism of the tumour cells, and a blood vessel, immediately underneath the affected area, completely blocked by tumour tissue.

Many areas of the lung are involved in an acute bronchopneumonia of pyogenic type and there is also partial resolution of older bronchopneumonic exudates.

OTHER ORGANS In the liver some congestion and bile retention is seen, no tumour deposits are present, and there is no evidence of amyloidosis. Amyloidosis is present in the spleen, the amyloid areas staining deeply with methyl violet.

Bronchial lymph nodes show anthracosis and sinus histiocytosis. Numerous sections of the prostate were examined and these show no evidence of malignancy. Some hypertrophic and inflammatory changes are seen. No tumour tissue is seen in the brain and meninges. The thyroid gland is moderately involuted with occasional large colloid-filled acini. The kidneys show patchy scarring of arteriosclerotic type, and there is a simple haemorrhagic cyst. No evidence of malignancy is seen in the pancreas. In the pituitary small cysts of the pars intermedia are present. The tubules of the right testis are rather atrophic. No significant histological changes are seen in the suprarenal glands.

\section{CASE 2}

V.L., a man aged 59, a factory supervisor (No. Radcliffe Infirmary 214086), in 1955 had a myocardial infarction and was put on a course of long-term anticoagulant treatment. In May 1959, he had an episode of acute pulmonary oedema. He then developed aching pains in both hips, extending down to the right leg, in which the pulses were absent.

In November 1959, endarteriectomy was performed on the right common iliac artery. The biopsy specimen (R.I.S.H. 7781/59) (Dr. W. C. D. Richards) was found to contain some masses of cells which, from a cytological point of view, were regarded as being almost certainly malignant in character. No primary tumour was discovered. A radiotranslucent area was found in the upper half of the right femur but a biopsy of the area showed nothing remarkable.

The patient developed increasing dyspnoea, congestive cardiac failure, and signs of chest disease, and died on 31 May 1961.

\section{NEGROPSY REPORT OF CASE 2}

A post-mortem examination (R.I. 499/61) was carried out by Dr. Gerald Manley. The positive findings included an early right-sided empyema thoracis and an encysted interlobar empyema between the upper and middle lobes of the right lung. There was a lobar pneumonia affecting the right upper and lower lobes. A careful search was made for a neoplasm in the lungs but none was found.

There was a fibrinous pericarditis. The heart showed an old healed posterior myocardial infarct and a recent infarct affecting the whole thickness of the interventricular septum and anterior part of the left ventricle. Both coronary arteries were completely occluded, about $2 \mathrm{~cm}$. from their origins, by brownish pultaceous material. The aorta showed a moderate degree of atheroma. Just above the bifurcation there was a little adherent mural thrombus, but the nature of this tissue quickly changed, as the bifurcation was approached, into white friable fleshy material with a vaguely polypoid structure in places. This mass extended from the bifurcation down the right common iliac artery, occluding it as far as the origin of the internal iliac artery. Distal to this there was a little thrombus which quickly petered out to leave a normal arterial tree beyond. Another limb of the fleshy white mass extended down the left common iliac artery for $2 \mathrm{~cm}$.

A small white nodule, $9 \mathrm{~mm}$. in diameter and well circumscribed, was found in the thyroid gland. It did not look malignant to the naked eye.

The adrenal glands showed very marked cortical hyperplasia. A stone was embedded in Hartmann's gall bladder pouch. A horse-shoe kidney was present. The median lobe of the prostate was hypertrophied and the bladder was slightly trabeculated.

\section{HISTOLOGY OF CASE 2}

The nodular adherent masses in the iliac vessels and at the aortic bifurcation contain some thrombus, but are largely composed of necrotic cellular tissue. Only at the periphery of the nodular masses and in its clefts are there any recognizable cells (Fig. 6), which have large vesicular nuclei, sometimes hyperchromatic or multiple, prominent nucleoli and indistinct eosinophilic cytoplasm. There is no recognizable cell pattern (Fig. 7).

The remaining organs show no evidence of primary or secondary neoplasia. The thyroid nodule is an adenoma of foetal type. There is myocardial fibrosis, lobar pneumonia and lymphadenitis of the tracheo-bronchial lymph nodes.

\section{DISCUSSION}

There can be little doubt concerning the malignant nature of the tissue found in case 1, although it may be noted that the metastases were apparently embolic in origin, both in the skin and in the lungs, 


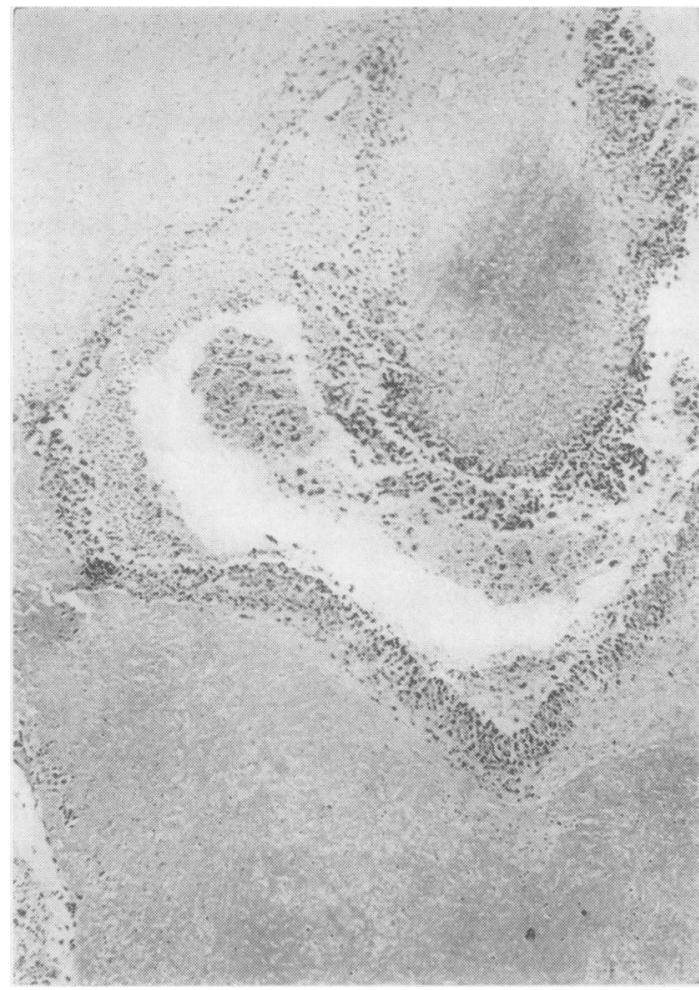

FIG. 6

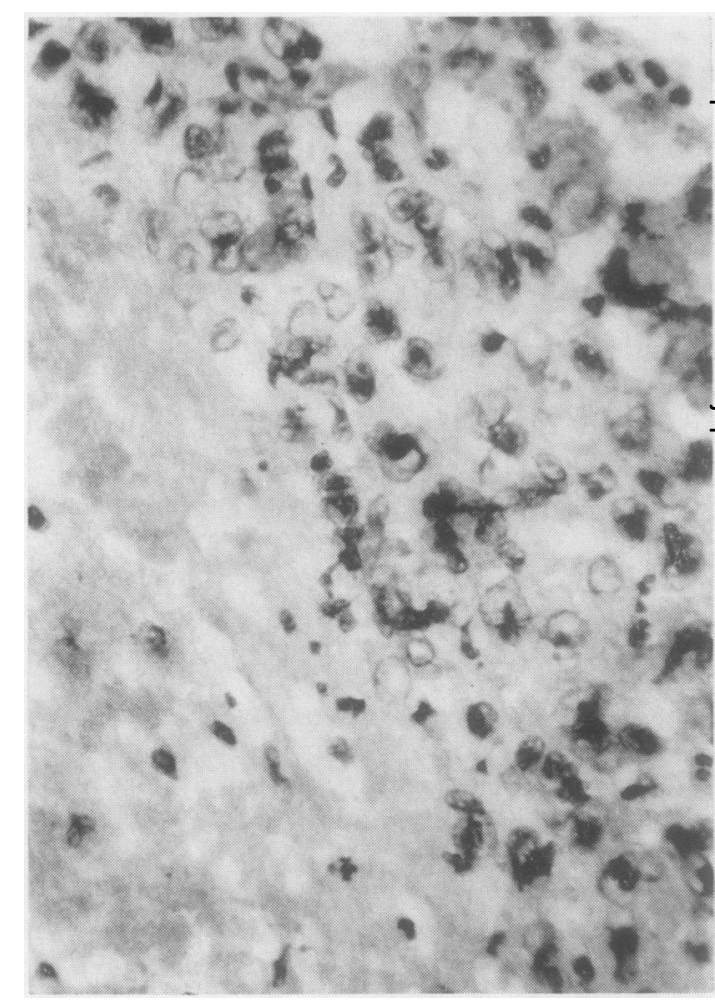

FIG. 7

FIG. 6. Case 2. Necrotic and cellular zones lining a cleft in the material removed from the lumen of the right commor尺

iliac artery. Haematoxylin and eosin $\times 30$.

FIG. 7. Case 2. Tumour cells and necrotic zone showing cell ghosts. Haematoxylin and eosin $\times 300$.

and even in these sites they showed some evidence of regression and replacement by fibrosis. The exact route taken by the emboli which reached the lungs was not determined. In case 2 the aortic tissue was similar to that in case 1 , but showed far more necrosis and only small areas of surviving cellular tissue. No metastases or tumour emboli were demonstrable.

From a cytological point of view, however, this tissue can also be regarded as malignant, and the similarity between these two cases prompted a search for similar cases in the literature. Aortic tumours of any type, whether primary or secondary, are very uncommon. Reported cases of primary aortic tumours were reviewed by Nencki (1946), but none of the four collected cases appears to have been intimal in origin and they were probably all derived from adventitial tissues.

Karhoff (1952) reported a mesenchymal tumour of the aorta, histologically appearing quite distinct from cases 1 and 2. This tumour is illustrated in Kaufmann's textbook of 'Special pathological anatomy' (Staemmler, 1954). Fibromyomatous. tumours of the aortic arch were reported by Détries (1960) and Kattus, Longmire, Cannon, Webb, ando Johnston (1960). Both these tumours arose in the subclavian region, and both occurred in youngs women.

Kovaleva and Press (1959) reported a primary? sarcoma of the aortic intima in a 65-year-old man $\rightarrow$ with secondary deposits in the pelvic bones. This case appears to be similar in type to the cases reported here. There was, in addition, amyloidosis of the liver and spleen. No evidence of a primary neo 0 plasm, other than in the aorta, could be found N Felder (1960) reported a case of aortic obstructiono caused by malignant tissue, with deposits in the pelvic bones and lungs, which he regarded asह being due to a tumour thrombus in the aorta? secondary to primary (multicentric) osteogenico sarcoma of the pelvis, or alternatively, secondary to. primary osteogenic sarcoma of the pelvis which ha@ also metastasized to other areas of the pelvis Examination of the malignant tissues from this 
case (by courtesy of Dr. Felder and Dr. R. I. Woodburn) shows a marked histological similarity to the malignant tissues in cases 1 and 2 . It is thus possible that the cases of Kovaleva and Press (1959) and Felder (1960) are further examples of primary sarcomata of the aortic intima.

It would, of course, be possible to argue that in these cases a small primary tumour elsewhere had been responsible for intraluminal aortic metastasis, as in the recently reported case of Schoene (1963), in which a malignant melanoma of the foot was eventually found.

In all the cases concerned, clinical investigations, the necropsies, and histological examination failed to demonstrate any possible primary neoplasm other than in the aorta itself (unless Felder's case is accepted as having been caused by osteogenic sarcoma), although in three of the cases there was histological evidence of malignant disease existing five months, 12 months, and 18 months before death.

If it is accepted that these tumours are aortic in origin, it must be assumed that they arose from aortic intimal tissues. Human aortic endothelium is probably capable of regeneration (Cotton, Harwood, and Wartman, 1961), and cellular abnormalities of the aortic endothelium increase in severity with the age of the subject (Ferrari and Forti, 1961). The endothelium is thus presumably capable of malignant proliferation. This must also be true of the other cellular components of the intimal zone.

The absence of capillary vasculature within the tumour masses is probably the reason for the widespread cellular necrosis, a surprising finding in view of the proximity of the aortic bloodstream. Only a limited thickness of cellular tissue is apparently permitted to survive by direct perfusion from the bloodstream. There seems also to be a distinct tendency for regression by fibrosis (and necrosis) of the tumour tissue, and the insignificant nature of the secondary deposits, when present, is noteworthy, having regard to the time presumably available for their proliferation and the opportunity for embolism afforded by the site of the tumour within the lumen of the aorta. The overall effect is to produce a tumour mass sufficiently like thrombus to be mistaken macroscopically, or even microscopically, for the latter, with very small secondary deposits in the lungs or pelvic bones (and possibly elsewhere) which might well be overlooked on superficial examination.

Although this condition must be extremely rare, it is nevertheless clear that more attention should be given to histological examination of material from occluded aortas and the larger blood vessels, and that this condition should be considered in patients whose response to treatment is disappointing, particularly if there has been a good initial response to arterial surgery.

I am grateful to my colleagues at Northampton General Hospital, especially Mr. E. E. T. Taylor, for their assistance, and to Dr. A. M. Cooke, Dr. W. C. D. Richards, and Dr. G. Manley of the Radcliffe Infirmary, Oxford, for the permission to publish details of case 2, including an abstract of the post-mortem report. I am also very grateful to Dr. B. O. Press for sending me photographic material from his case, and to Dr. D. A. Felder and Dr. R. L. Woodburn for sending me material.

Dr. A. H. T. Robb-Smith kindly allowed the use of the photographic facilities of the Department of Morbid Anatomy, Radcliffe Infirmary, and he has also discussed these cases with me. Dr. T. Parry has given much valuable assistance with the photography.

\section{REFERENCES}

Cotton, R. E., Harwood, T. R., and Wartman, W. B. (1961), J. Path. Bact., 81, 175.

Détrie, P. (1960). J. Chir. (Paris), 80, 666.

Felder, D. A. (1960). Minn. Med., 43, 392.

Ferrari, E., and Forti, E. (1961). Riv. Anat. pat., 19, 146.

Kattus, A. A. Jr., Longmire, W. P., Cannon, J. A., Webb, R., and Johnston, C. (1960). New Engl. J. Med., 262, 694.

Karhoff, B. (1952). Zbl. allg. Path. path. Anat., 89, 46.

Kovaleva, A. N., and Press, B. O. (1959). Arkh. Pat., 10, 62.

Lendrum, A. C. (1947). In Recent Advances in Clinical Pathology, edited by S. C. Dyke, p. 452. Churchill, London.

Nencki, L. (1946). Cardiologia (Basel), 10, 1.

Schoene, R. H. (1963). Ohio St. med. J., 59, 695.

Staemmler, M. (1954). In Kaufmann's Lehrbuch der Speziellen Pathologischen Anatomie, 11 th-12th ed., edited by M. Staemmler, vol. 1, p. 377. de Gruyter, Berlin. 